\title{
A Pediatric Case of Papular Epidermal Nevus With "Skyline" Basal Cell Layer (PENS)
}

\author{
Federico Strambach ${ }^{1}$, Vincenzo Piccolo ${ }^{2}$, Andrea Ronchi ${ }^{3}$, Teresa Russo ${ }^{2}$, \\ Giuseppe Argenziano ${ }^{2}$, Elvira Moscarella ${ }^{2}$
}

1 Dermatology Unit, Hospital Gral. de Agudos Carlos G. Durand, Buenos Aires, Argentina
2 Dermatology Unit, University of Campania, Luigi Vanvitelli, Naples, Italy
3 Pathology Unit, University of Campania, Luigi Vanvitelli, Naples, Italy

Key words: PENS, dermoscopy, epidermal nevus, pediatric dermatology

Citation: Strambach F, Piccolo V, Ronchi A, Russo T, Argenziano G, Moscarella E. A pediatric case of papular epidermal nevus with "skyline" basal cell layer (PENS). Dermatol Pract Concept. 2019;9(4):313-314. DOI: https://doi.org/10.5826/dpc.0904a17

Accepted: May 14, 2019; Published: October 31, 2019

Copyright: @2019 Strambach et al. This is an open-access article distributed under the terms of the Creative Commons Attribution License, which permits unrestricted use, distribution, and reproduction in any medium, provided the original author and source are credited.

Funding: None.

Competing interests: The authors have no conflicts of interest to disclose.

Authorship: All authors have contributed significantly to this publication.

Corresponding author: Elvira Moscarella, MD, University of Campania, Luigi Vanvitelli Dermatology Unit, Via Pansini 5, 80131 Naples, Italy. Email: elvira.moscarella@gmail.com

\section{Introduction}

Papular epidermal nevus with "skyline" basal cell layer (PENS) is an infrequent type of epidermal nevus, clinically characterized by hyperkeratotic papules or plaques. Dermatological lesions have been described alone or associated with other symptoms as part of a syndrome. We describe a new case of this rare entity.

\section{Case Presentation}

A 5-year-old boy presented with multiple keratotic whitish plaques that were asymptomatic and randomly distributed on the buttocks, abdomen, and upper and lower limbs and had been increasing in number since birth (Figure 1, A and B). Dermoscopy of a lesion on the right leg revealed a homogeneous white pattern with well-defined borders. A lesion on the abdomen presented a homogeneous brown pigmentation, with hyperpigmented and well-defined borders, resembling leaf-like areas described in basal cell carcinoma (Figure 1, C and $\mathrm{D}$ ). The clinical differential diagnosis included mainly common keratinocytic nevi, viral warts, flat warts, and mosaicism of waxy keratosis of childhood, which differs clinically in shape, pattern of distribution, and number of lesions.

Biopsy taken from the lesion on the abdomen showed compact orthokeratotic hyperkeratosis, acanthosis with broad and rectangular rete ridges, and a basal cell layer with a striking palisaded arrangement of basal cell nuclei (Figure 2). With these features, PENS was diagnosed. Neurological examination of the patient was normal, and the follow-up to date has not shown neurological disorders. There is no history of similar lesions in the patient's family.

\section{Discussion}

Torrelo et al [1] first reported 5 cases with lesions clinically described as asymptomatic single or multiple keratotic papules or plaques with a rough, flat surface, whitish to brown color, and variable shape. None of the patients had a family history of similar lesions or other extracutaneous manifestations. Histopathological features included compact orthokeratotic hyperkeratosis, acanthosis with broad and rectangular 
rete ridges, and a basal cell layer with a striking palisaded arrangement of basal cell nuclei that resembled the "skyline" or "eyeliner" pattern described in Bowen disease.

Although Torrelo described randomly distributed lesions, a case of blaschkoid distribution has been reported [2].

Tadini et al [3] reported neurological disorders in 5 of 6 patients described with PENS, coining the term PENS syndrome [3]. These neurological conditions can improve during childhood and adolescence. A positive relationship has been suggested between PENS syndrome and the presence of more than 4 clinical lesions [4].

Family cases have been reported. Although different theories try to explain familial occurrence of PENS, a paradominant inheritance seem to be the most likely inheritance pattern.

Regarding dermoscopy, 2 different patterns were present in our patient: a lesion with white homogeneous pattern and well-defined border, as already described by Balestri et al [5], and a second one with hyperpigmented and well-defined borders, resembling leaflike areas as described in basal cell carcinoma.

\section{Conclusions}

We describe a new case of PENS showing 2 different dermoscopic patterns in the same patient. Because reports of PENS are scarce, we support the idea that more cases should be described in order to find a distinctive pattern of this keratinocytic nevus.

\section{References}

1. Torrelo A, Colmenero I, Kristal L, et al. Papular epidermal nevus with "skyline" basal cell layer (PENS). J Am Acad Dermatol. 2011;64(5):888-892.

2. Faure E, Tadini G, Brena M, Cassulini LR. Papular epidermal nevus with "skyline” basal cell layer (PENS) following a Blaschko linear pattern. Pediatr Dermatol. 2013;30(6):e270-e271.

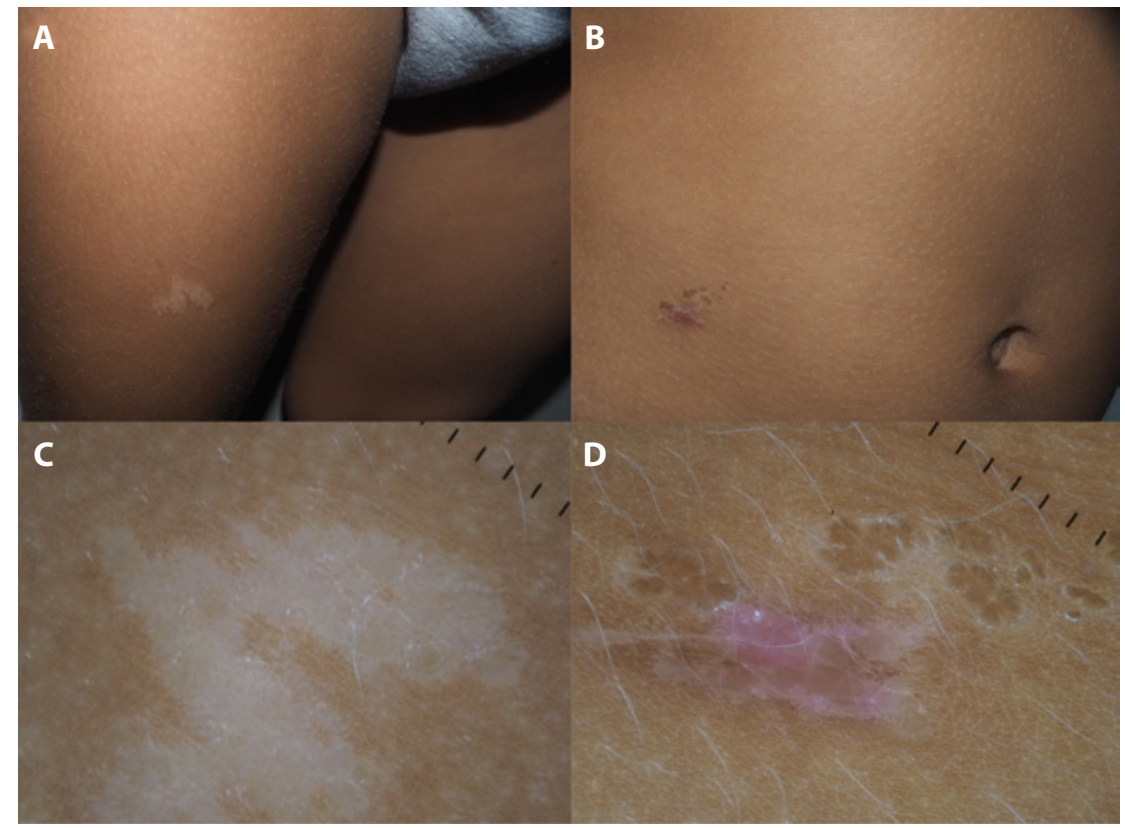

Figure 1. $(A, B)$ Multiple keratotic whitish plaques on the patient's arms and abdomen, increasing in number since birth, asymptomatic. (C) Dermoscopy of a lesion on the right leg revealed a homogeneous white pattern with well-defined borders. (D) One lesion on the abdomen presented a homogeneous brown pigmentation, with hyperpigmented and well-defined borders, resembling leaf-like areas described in basal cell carcinoma. [Copyright: (02019 Strambach et al.]

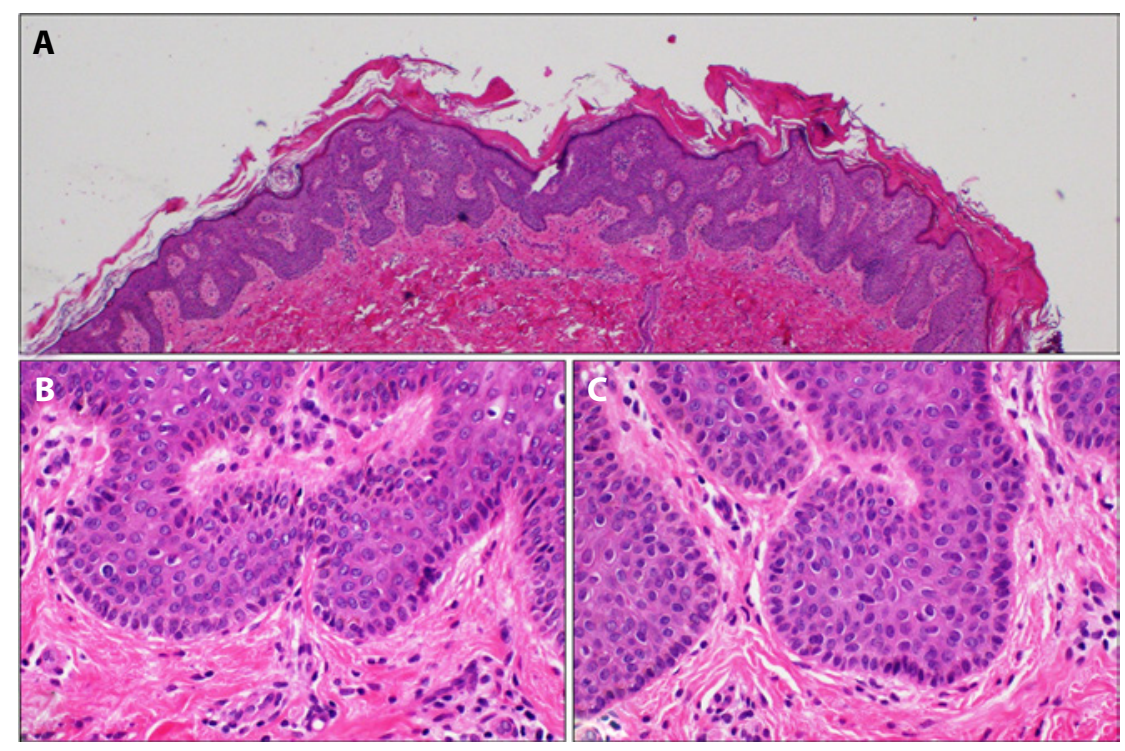

Figure 2. Histopathologically, (A) compact orthokeratotic hyperkeratosis, acanthosis with broad and rectangular rete ridges, and a basal cell layer with a striking palisaded arrangement of basal cell nuclei were seen. (B,C) Higher magnification of palisade arrangement of the basal cell nuclei. [Copyright: @2019 Strambach et al.]

3. Tadini G, Restano L, Happle R, Itin P. PENS syndrome: a new neurocutaneous phenotype. Dermatology. 2012;224(1):24-30.

4. Luna PC, Pannizardi AA, Martin CI, et al. Papular epidermal nevus with skyline basal cell layer (PENS): three new cases and review of the literature. Pediatr Dermatol. 2016;33(3):296-300.

5. Balestri R, Rizzoli L, Reach J, Girardelli CR. Dermoscopy of popular epidermal nevus with skyline basal cell layer. Pediatr Dermatol. 2017;34(2):e99-e101. 